\title{
Immobilized Polymer Fraction in Hyperbranched Polymer/Silica Nanocomposite Suspensions
}

\author{
Riccardo Ruggerone, Valérie Geiser, Sara Dalle Vacche, Yves Leterrier,* and \\ Jan-Anders E. Månson \\ Laboratoire de Technologie des Composites et Polymères (LTC), Ecole Polytechnique Fédérale de Lausanne \\ (EPFL), CH-1015 Lausanne, Switzerland
}

Received September 7, 2010; Revised Manuscript Received November 23, 2010

\begin{abstract}
The glass transition behavior of hyperbranched polymer (HBP) molecules with suspensions of silica and glass particles up to the concentrated regime $(25 \mathrm{vol} \%)$ was analyzed by modulated differential scanning calorimetry (MDSC). The reversing and nonreversing components of the MDSC signal were measured on suspensions of untreated and silylated particle of size in the nanometer and micrometer ranges. The heat capacity step $\left(\Delta C_{p}\right)$ at the glass transition of the HBP was found to be independent of silica loading for microparticles, whereas it decreased with increasing particle amount in the case of nanoparticles. A similar behavior was observed for the enthalpy relaxation. These changes in chain dynamics and the progressive suppression of aging were attributed to immobilization effects of the HBP at the surface of the particles, which became detectable only in the case of a very high specific surface. The immobilized HBP fraction was assumed to form a shell of constant thickness around individual particles and was calculated from the $\Delta C_{p}$ at the transition. In the case of untreated particles with a silanol surface, the immobilized shell was formed by HBP molecules H-bonded to the particles. The thickness of the shell was found to be equal to $1.9 \mathrm{~nm}$, which corresponded to half the size of the HBP. In the case of methacrylsilane-treated silica, the immobilized shell thickness was found to be equal to $1.3 \mathrm{~nm}$, which corresponded to a monolayer of covalently bound silane.
\end{abstract}

\section{Introduction}

Polymer nanocomposites have attracted the attention of a large amount of researchers because of their outstanding mechanical, thermal, and barrier properties. ${ }^{1-7}$ Major efforts have been devoted to their synthesis and processing and to analyze their properties as detailed in several reviews. ${ }^{8-10}$ The improved thermomechanical properties of nanocomposites with respect to microcomposites are usually attributed to the very high specific surface area to volume ratio of nanoparticles. ${ }^{11-13}$ In this case, the fraction of polymer chains immobilized on the surface of the particles due to strong interfacial interactions and confined between nanoparticles can be significant. The consequences of such immobilization and confinement phenomena are in the first place in terms of rheological properties, with huge increases in viscosity $^{14-17}$ and liquid-to-solid transition at particle fractions as low as $10 \mathrm{~mol} \% .{ }^{18}$ Changes in the glass transition temperature $\left(T_{\mathrm{g}}\right)$ have also been reported and analyzed for instance by Bansal et al., who established a quantitative equivalence between nanocomposites and supported thin polymer films. ${ }^{19}$ This result was questioned by Kropka et al., who demonstrated that a quantitative equivalence between the behaviors of these two systems cannot be established in general. ${ }^{20}$ These authors also developed scaling arguments to quantitatively predict the properties of polymer nanocomposites using thin film data. In the case of strong interactions with the substrate, thin films of less than 100 $\mathrm{nm}$ showed increased $T_{\mathrm{g}}$ with respect to the bulk polymer. ${ }^{21-23}$ For both supported thin films and polymer nanocomposites, a gradient of $T_{\mathrm{g}}$ in the interfacial region and the suppression of physical aging were proposed. ${ }^{24-26}$ In contrast, Koh and Simon indicated that supported thin films with neutral interfaces age

*Corresponding author. E-mail: yves.leterrier@epfl.ch. similarly to the bulk when changes in $T_{\mathrm{g}}$ are accounted for, ${ }^{27}$ whereas work by Huang and Paul on micrometer-thick films indicates an acceleration of aging effects. ${ }^{28,29}$ All these findings were attributed to the presence of a fully or partially immobilized polymer layer near the nanoparticle or substrate surface.

However, the analysis and quantification of the thickness of such an immobilized layer remain challenging. Efficient techniques to this end include solid-state nuclear magnetic resonance (NMR) and differential scanning calorimetry (DSC). NMR was applied to filled rubbers by studying the magnetization decay after a pulse sequence of a magnetic field. ${ }^{30-32}$ The relaxation process showed a fast decaying component corresponding to unbound matrix and a slow decaying component corresponding to the bound matrix from which the immobilized layer thickness was estimated to be in the range $1-2 \mathrm{~nm} .{ }^{30}$ DSC was also used both in the step scan and in the modulated scan configurations to quantify the immobilized matrix fraction in nanocomposites. ${ }^{33,34}$ One indication of the existence of an immobilized fraction is the decrease in the heat capacity step at the glass transition with respect to the nonfilled polymer because the immobilized fraction does not take part in the relaxation process. ${ }^{35,36}$ The results were consistent with those of the NMR experiments, with immobilized layers of 1-2 $\mathrm{nm}$.

The present paper investigates the immobilization of acrylated hyperbranched polymers (HBP) on the surface of silica nanoparticles. HBP are highly branched macromolecules belonging to the family of dendritic polymers. The properties of HBP have been extensively investigated in other studies. ${ }^{37-39}$ HBP exhibit low Newtonian viscosity due to their globular structure and lack of entanglements. For this reason they have been used as lowviscosity toughening additives to thermosets. ${ }^{40}$ Acrylated HBP also show low polymerization shrinkage, especially in the presence of nanoparticles, and low internal stress with respect to conventional 
resins. ${ }^{41-43}$ However, nanoparticles were found to dramatically increase the viscosity of HBP suspensions, by more than 5 orders of magnitude upon addition of $20 \mathrm{vol} \%$ of silica. ${ }^{44}$ Such an increase exceeds by far that obtained with oligomers and linear polymer suspensions, ${ }^{45}$ which was argued to result from the immobilization of HBP molecules on the surface of the particles and gelation of the HBP-particles network. The thickness of this layer was estimated to be in the range $2-7 \mathrm{~nm}$ depending on the surface chemistry, concentration, and dispersion state of the particles. $^{44}$

The objective of the present work was to further investigate the influence of silica nanoparticles on the immobilization of acrylated HBP molecules. Particle suspensions in the HBP with two different surface chemistries and a range of concentrations were prepared, and their heat capacity changes at the glass transition were analyzed using modulated DSC (MDSC). A first step was devoted to the optimization of the modulation parameters to avoid artifacts in the determination of the heat capacity.

\section{Materials and Methods}

Materials. The monomer was an acrylated third-generation hyperbranched polyether polyol with $\sim 29$ acrylate groups (Perstorp AB, Sweden). Two kinds of amorphous silica nanoparticles were used. The first were silica organosols supplied in the form of a $30 \mathrm{wt} \%$ suspension of $\mathrm{SiO}_{2}$ in isopropanol (HL, Highlink NanO G502, Clariant). The particles are slightly hydrophobic with a density equal to $2 \mathrm{~g} / \mathrm{cm}^{3}$ and average size of $13 \mathrm{~nm} .{ }^{44}$ The corresponding specific surface was equal to $230 \mathrm{~m}^{2} / \mathrm{g}$. The second were methacrylsilane-treated silica particles supplied in powder form with a specific surface equal to $150 \pm 25 \mathrm{~m}^{2} / \mathrm{g}$ (AS, Aerosil R7200, Degussa). These particles were based on fumed silica aggregates of $12 \mathrm{~nm}$ primary particles (Aerosil 200), with a density equal to $2.2 \mathrm{~g} / \mathrm{cm}^{346}$ and specific surface equal to $200 \mathrm{~m}^{2} / \mathrm{g}^{47,48}$ (values in the range $180-200 \mathrm{~m}^{2} / \mathrm{g}$ were also reported using BET and scattering methods ${ }^{49}$ ). Micron-sized glass spheres (GS, Sigma-Aldrich) of size 9-13 $\mu \mathrm{m}$ and specific surface equal to $\sim 0.1 \mathrm{~m}^{2} /$ g (i.e., 3 orders of magnitude smaller than the nanoparticles) were also used.

HBP suspensions with silica concentrations up to $25 \mathrm{vol} \%$ were prepared by ultrasonic mixing as described in detail elsewhere. ${ }^{41}$ The AS powder was first dispersed in isopropanol (ratio $1: 3$ by weight) and processed with ultrasound (Digital Sonifier 450 , Branson) for 10 periods of $30 \mathrm{~s}$ to avoid excessive heating. The AS suspension was then mixed with the HBP at selected concentrations and stirred for $1 \mathrm{~h}$. The HL suspension was directly mixed with the HBP with no prior ultrasonication and stirred for $1 \mathrm{~h}$. In both cases the solvent was evaporated at $40^{\circ} \mathrm{C}$ under vacuum for a minimum of $24 \mathrm{~h}$, until no further weight loss could be measured. The GS particles were also directly mixed with the HBP and stirred for $1 \mathrm{~h}$. The dispersion of the silica nanoparticles in the HBP was studied by transmission electron microscopy of thin section of cured nanocomposites (TEM, Philips CM12 operating at $120 \mathrm{kV}$ ). The dispersion of the glass microparticles was analyzed using optical microscopy of GS/ HBP suspensions squeezed between two glass slides (Olympus BX-60). As shown in Figure 1, it is evident that the two nanocomposites exhibited a markedly different morphology. While the $\mathrm{SiO}_{2}$ particles were well dispersed in the HL composites, they were strongly agglomerated in the AS composites with a very broad size distribution. A relatively good dispersion was observed for the GS microcomposites, characterized by a broad size distribution of the glass spheres.

Modulated DSC (MDSC). Temperature-modulated DSC scans (Q100, TA Instruments) were performed with HL, AS, and GS suspensions. The DSC was calibrated using sapphire and indium standards. An "ad hoc" calibration for heat capacity measurements was performed according to the manufacturer instructions, using a rate of $1 \mathrm{~K} / \mathrm{min}$, an amplitude of $1{ }^{\circ} \mathrm{C}$, and a period of $100 \mathrm{~s}$. The tests were carried out immediately after
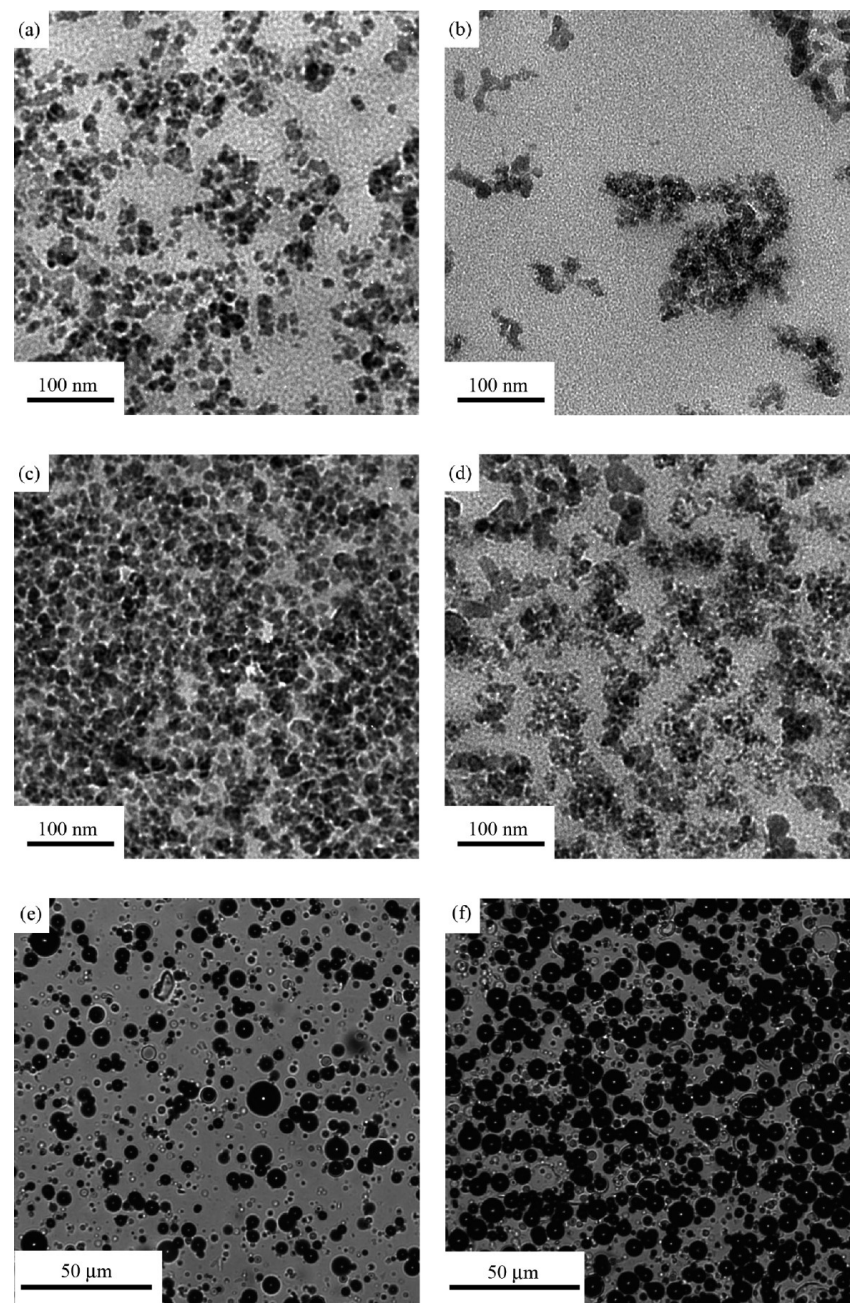

Figure 1. TEM images of silica/HBP nanocomposites (a: HL $5 \mathrm{vol} \%$; b: AS 5 vol \%; c: HL $20 \mathrm{vol} \%$; d: AS $20 \mathrm{vol} \%$ ) and optical micrographs of suspensions of glass microspheres in HBP (e: GS $10 \mathrm{vol} \%$; f: GS 20 vol \%).

calibration. The sample mass was set between 10 and $20 \mathrm{mg}$, and samples were put into crimped aluminum pans. The reversing and nonreversing components of the heat capacity of the suspensions were analyzed between -90 and $-35^{\circ} \mathrm{C}\left(-30^{\circ} \mathrm{C}\right.$ for the suspension with $20 \mathrm{vol} \% \mathrm{HL}$ ). The HL and GS samples were first cooled to $-90{ }^{\circ} \mathrm{C}$ at $1 \mathrm{~K} / \mathrm{min}$ and then heated at the same rate. For the AS suspensions only the heating rate was controlled at $1 \mathrm{~K} / \mathrm{min}$, and the nonreversing heat capacity was not recorded (for detailed explanations see the MDSC Protocol section). The reproducibility of the MDSC experiments was checked with the HBP making a second scan with the same parameters as the first scan. The variation in heat capacity values was of the order of $2 \%$, i.e., smaller than the error of the heat capacity step $\left(\Delta C_{p}\right)$ at $T_{\mathrm{g}}$ reported in the Results section.

The reversing component of the heat capacity included the contributions of the HBP and of the silica. The contribution of the HBP phase $\left(C_{p, \mathrm{HBP}}\right)$ which will be analyzed in the following sections was obtained from a mass balance:

$$
C_{p, \mathrm{HBP}}=\frac{\left(C_{p} m\right)-\left(C_{p, \text { silica }} m_{\text {silica }}\right)}{m_{\mathrm{HBP}}}
$$

where $C_{p}$ and $C_{p \text {,silica }}$ are the reversing heat capacities of the sample and of amorphous silica, respectively, $m$ is the total mass of the sample, and $m_{\text {silica }}$ and $m_{\mathrm{HBP}}$ are the corresponding masses of silica and HBP. The heat capacity of silica as a function of temperature was obtained from tabulated data. ${ }^{50}$ In the case of 
silane-treated AS particles, the actual mass of silica $(95 \pm 1 \%$ of the mass of the particles according to the supplier, the rest being the silane) was used. The contribution of the methacrylsilane, which was unknown, was thus included in the heat capacity of the polymer. For this reason a 5\% error (corresponding to the mass of silane) was included in the error in $C_{p, \mathrm{HBP}}$. A careful determination of the modulation parameters was performed in a first step, as detailed in the MDSC Protocol section.

Fourier Transform Infrared Attenuated Total Reflectance Spectroscopy. Fourier transform infrared attenuated total reflectance (FTIR-ATR) spectra of the AS and HL powders were recorded with a Nicolet 6700 spectrometer equipped with a Smart iTR accessory. The spectra were acquired with 32 scans and a resolution of $4 \mathrm{~cm}^{-1}$. The $\mathrm{HL}$ solution was left in vacuum at $50{ }^{\circ} \mathrm{C}$ for $48 \mathrm{~h}$ in order to completely evaporate the isopropanol and collect the silica particles, and all the samples were stored at $80{ }^{\circ} \mathrm{C}$ under vacuum prior to collecting the spectra. As the spectra of pure HBP and silica showed extensive overlap, the spectra of silica suspensions in HBP did not provide useful insights due to insufficient signal sensitivity and were not considered.

MDSC Protocol. The optimal experimental conditions in terms of scan rate, amplitude, and modulation period were established with the pure HBP and with a $25 \mathrm{vol} \% \mathrm{HL}$ suspension. The principle of the measurement consists in the superposition of an oscillating sinusoidal signal to the heating ramp of a conventional DSC. A theoretical description of the MDSC technique can be found elsewhere. ${ }^{51,52}$ The advantages related to temperature modulation are an increased sensibility to small transitions, the possibility of evaluating the materials heat capacity, and separating reversing and nonreversing phenomena within one single measurement. In fact, numerical simulations suggested that the choice of modulation parameters (heating or cooling rate and period of oscillating signal) was critical to obtain exploitable results. The measured $T_{\mathrm{g}}$ and heat capacity step at the transition were for instance found to depend on the modulation period and cooling rate..$^{53-57}$ In practice, scan rates below $5 \mathrm{~K} / \mathrm{min}$ were strongly advised to decrease the baseline steepness and enable high instantaneous temperature variations (high amplitudes). A minimum of 4-5 complete oscillations during the transition was moreover recommended by the manufacturer. Using these precautions, MDSC should provide correct estimates of both the $\Delta C_{p}$ at $T_{\mathrm{g}}$ and the magnitude of enthalpy relaxation.

The suspensions were in an equilibrium state at room temperature and were first cooled below their glass transition down to $-90{ }^{\circ} \mathrm{C}$. According to Simon and McKenna, the cooling rate from the liquid must be smaller than or equal to the heating rate to avoid physical aging upon heating and provide reasonable estimates of the integral of the enthalpy relaxation peak, as detailed in refs 58 and 59. Therefore, the cooling rate was set equal to the heating rate $(1 \mathrm{~K} / \mathrm{min})$ for the $\mathrm{HBP}$ and $\mathrm{HL}$ suspensions. In addition, annealing for $3 \mathrm{~h}$ at $-90{ }^{\circ} \mathrm{C}$ did not determine a significant increase of the enthalpy relaxation peak intensity; hence, the measurements were performed without annealing.

Figure 2 shows the influence of the modulation parameters on the reversing heat capacity of pure HBP and HBP containing $25 \mathrm{vol} \% \mathrm{HL}$. The data for the HL nanosuspensions were not normalized with respect to the HBP mass because only qualitative results were searched. The influence of the heating rate for a fixed period of $100 \mathrm{~s}$ and amplitude of $\pm 1{ }^{\circ} \mathrm{C}$ is depicted in Figure 2a. It is evident that increasing the rate beyond $2 \mathrm{~K} / \mathrm{min}$ shifted the curves toward higher temperatures and decreased the $\Delta C_{p}$ at $T_{\mathrm{g}}$ as was observed in previous studies. ${ }^{56,57}$ In contrast, below $2 \mathrm{~K} / \mathrm{min}$ the thermal response stabilized, and a scan rate of $1 \mathrm{~K} / \mathrm{min}$ was selected for the work. The influence of the period with a fixed scan rate of $1 \mathrm{~K} / \mathrm{min}$ and amplitude of $\pm 1{ }^{\circ} \mathrm{C}$ is shown in Figure 2b. Decreasing the oscillation period (i.e., increasing the local heating rate) had the same effects; i.e., it

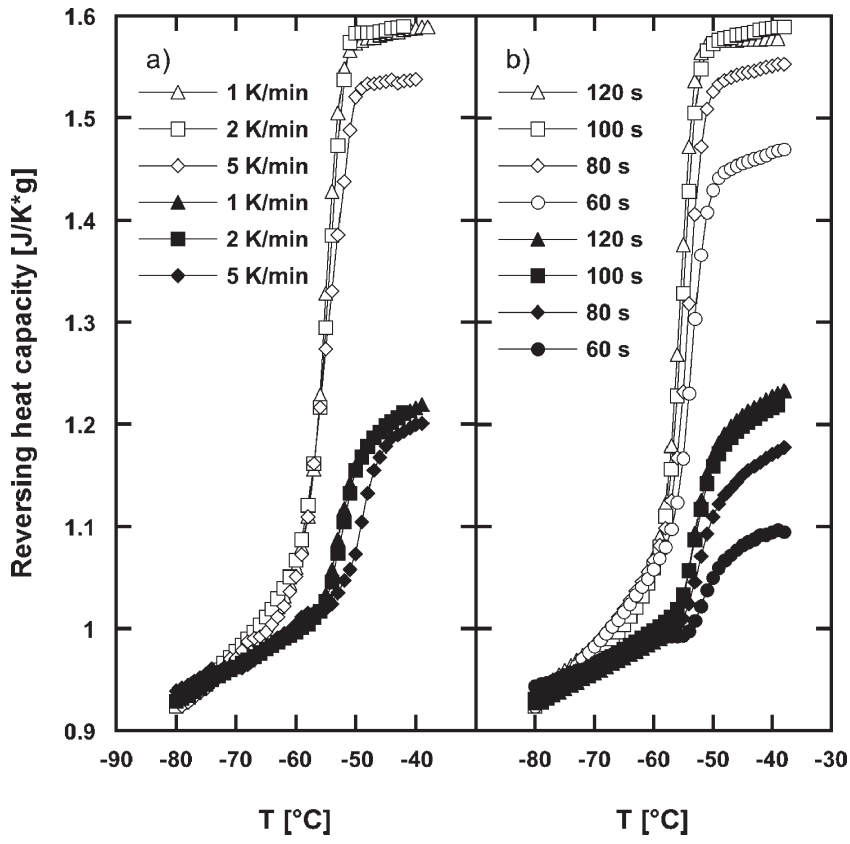

Figure 2. Influence of the modulation parameters (a: heating rate in the range of $1-5 \mathrm{~K} / \mathrm{min}$; b: period in the range $60-120 \mathrm{~s}$ ) on the reversing heat capacity of pure HBP (open symbols) and a 25 vol \% HL suspension (full symbols).

shifted the reversing heat capacity curves toward higher temperatures and decreased the $\Delta C_{p}$ at $T_{\mathrm{g}}$ as also reported elsewhere. ${ }^{53-57}$ These effects stabilized for periods above $100 \mathrm{~s}$; hence, a period of $120 \mathrm{~s}$ was selected for the work. Varying the oscillation amplitude between \pm 0.5 and $\pm 1{ }^{\circ} \mathrm{C}$ at a fixed scan rate and period (these data are not shown) did not lead to significant variation in the heat capacity signal; hence, an amplitude of $\pm 1^{\circ} \mathrm{C}$ was selected. It was moreover observed that the combination of parameters such that the derivative of the modulated temperature as a function of time became negative gave very similar results to "heat only" scans where the derivative was always positive. The selected parameters (scan rate of $1 \mathrm{~K} / \mathrm{min}$, period of $120 \mathrm{~s}$, and an amplitude of $\pm 1^{\circ} \mathrm{C}$ ) guaranteed seven complete oscillations during the glass transition.

\section{Results}

Figure 3 compiles the reversing heat capacity for the HBP fraction in the HL, AS, and GS suspensions obtained from the MDSC thermograms using eq 1 . The $T_{\mathrm{g}}$ was determined at the inflection point of the curves, and the values are reported in Table 1. The $\Delta C_{p}$ at $T_{\mathrm{g}}$ was calculated from the distance between the two tangents to the data in the glassy and rubbery states away from the transition, and the data are also reported in Table 1. In the glassy state the tangent was taken between -80 and $-70{ }^{\circ} \mathrm{C}$ and in the rubbery state between -48 and $-38^{\circ} \mathrm{C}\left(-45\right.$ and $-35^{\circ} \mathrm{C}$ for the $20 \mathrm{vol} \% \mathrm{HL}$ suspension). As already pointed out by other authors, the tangent line method is prone to errors. ${ }^{33}$ Moreover, the choice of the inflection point (at the glass transition temperature, at the midpoint or at the onset point) could have some effect on the calculations. In the present work the error on the $\Delta C_{p}$ data reported in Table 1 was estimated to be about $5 \%$ for the HL and GS suspensions based on the errors in the determination of the slopes of the tangents and of the location of the inflection point and was calculated for the AS suspensions using partial derivatives of eq 1 to include the additional error resulting from the unknown contribution of the methacrylsilane.

For both HL and AS suspensions the $\Delta C_{p}$ at $T_{\mathrm{g}}$ decreased with increasing silica amount. These results suggest an immobilization effect of the HBP molecules on the nanoparticles, which appeared 


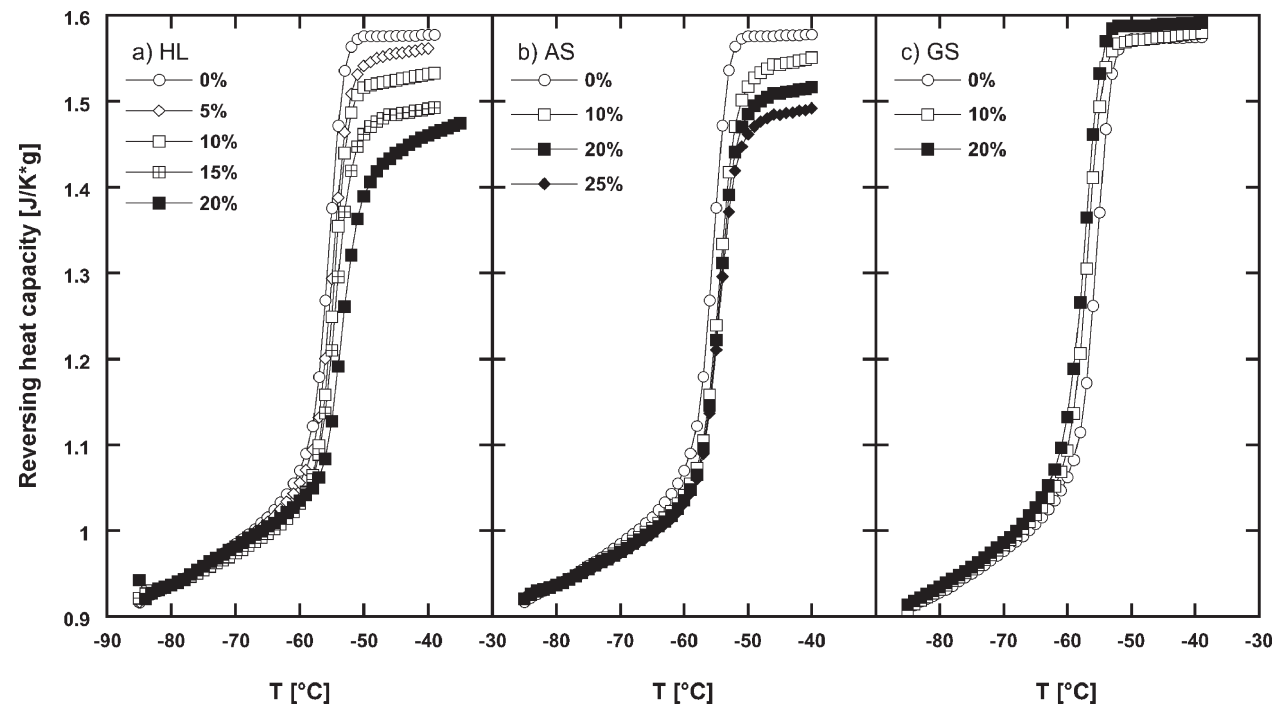

Figure 3. Reversing heat capacity of the HBP fraction in HL (a), AS (b), and GS (c) silica suspensions at different concentrations (vol \% indicated in the graphs).

Table 1. Glass Transition Temperature $T_{\mathrm{g}}$, Heat Capacity Step $\Delta C_{p}$, and Enthalpy Relaxation Strength $\Delta H_{\mathrm{r}}$ at $T_{\mathrm{g}}$ for HL, AS, and GS Suspensions

\begin{tabular}{|c|c|c|c|c|c|c|c|c|c|}
\hline \multirow{2}{*}{$\begin{array}{l}\text { particle volume } \\
\text { fraction [\%] }\end{array}$} & \multicolumn{3}{|c|}{ HL suspensions } & \multicolumn{3}{|c|}{ AS suspensions } & \multicolumn{3}{|c|}{ GS suspensions } \\
\hline & $T_{\mathrm{g}}\left[{ }^{\circ} \mathrm{C}\right]$ & $\Delta C_{p}[\mathrm{~J} /(\mathrm{K} \mathrm{g})]$ & $\Delta H_{\mathrm{r}}[\mathrm{J} /(\mathrm{K} \mathrm{g})]$ & $T_{\mathrm{g}}\left[{ }^{\circ} \mathrm{C}\right]$ & $\Delta C_{p}[\mathrm{~J} /(\mathrm{K} \mathrm{g})]$ & $\Delta H_{\mathrm{r}}^{a}[\mathrm{~J} /(\mathrm{K} \mathrm{g})]$ & $T_{\mathrm{g}}\left[{ }^{\circ} \mathrm{C}\right]$ & $\Delta C_{p}[\mathrm{~J} /(\mathrm{K} \mathrm{g})]$ & $\Delta H_{\mathrm{r}}[\mathrm{J} /(\mathrm{K} \mathrm{g})]$ \\
\hline 0 & -55.8 & $0.542 \pm 0.027$ & 0.41 & -55.8 & $0.542 \pm 0.027$ & & -55.8 & $0.542 \pm 0.027$ & 0.41 \\
\hline 5 & -55.2 & $0.508 \pm 0.025$ & 0.36 & & & & & & \\
\hline 10 & -54.6 & $0.484 \pm 0.024$ & 0.33 & -54.7 & $0.506 \pm 0.033$ & & -57.2 & $0.529 \pm 0.026$ & 0.38 \\
\hline 15 & -54.5 & $0.454 \pm 0.023$ & 0.28 & & & & & & \\
\hline 20 & -53.5 & $0.411 \pm 0.021$ & 0.19 & -54.6 & $0.467 \pm 0.041$ & & -57.8 & $0.563 \pm 0.028$ & \\
\hline 25 & & & & -54.6 & $0.451 \pm 0.047$ & & & & \\
\hline
\end{tabular}

${ }^{a}$ Not measured due to uncontrolled cooling conditions.

to be more pronounced for the HL suspensions than for the AS suspensions. The $T_{\mathrm{g}}$ of HL and AS suspensions was also found to be higher than that of the pure HBP. Interestingly, the $T_{\mathrm{g}}$ of the HL suspensions progressively increased with increasing silica fraction, in contrast to the AS suspensions, the $T_{\mathrm{g}}$ of which was independent of the amount of silica. It was checked that these changes in $T_{\mathrm{g}}$ were not artifacts resulting from differences in thermal properties between the different suspensions. In fact, if the variations in $T_{\mathrm{g}}$ were related to thermal lag effects, increasing the heating rate would cause large changes in the transition temperatures. But as shown in Figure 2, when the heating rate was increased from 1 to $5 \mathrm{~K} / \mathrm{min}$, only small shifts in temperature were found for the neat HBP and for the HL nanocomposite.

In contrast, as shown in Figure $3 \mathrm{c}$, the $\Delta C_{p}$ at $T_{\mathrm{g}}$ for the GS microsuspensions did not decrease with increasing particle fraction. This suggests that even if similar immobilization effects as for the HL nanocomposites occurred, they were not detectable because of the small specific surface of the GS particles. For this reason calculations of the immobilized layer thickness were not carried out for the GS microsuspensions. It was also evident that the $T_{\mathrm{g}}$ of the GS suspensions decreased with increasing particle fraction. The same effect was reported for nanocomposite materials ${ }^{60}$ and presumably reflected the reduction in interfacial interactions due to a lower density of $\mathrm{OH}$ groups on the surface of the glass compared to that of the silica (see, e.g., ref 61).

A similar behavior was evident with the enthalpy recovery peaks displayed in Figure 4 for the HL and GS suspensions. We did not calculate the enthalpy relaxation since the integration of the nonreversing signal was considered to be inaccurate due to undershoots. (It was estimated to be $\sim 2.5 \mathrm{~J} / \mathrm{g}$ for pure HBP and $1.3 \mathrm{~J} / \mathrm{g}$ for $25 \mathrm{vol} \% \mathrm{HL}$, and such a difference is significant compared to the typical $\pm 0.1 \mathrm{~J} / \mathrm{g}$ error for such measurements. ${ }^{58,59}$ )

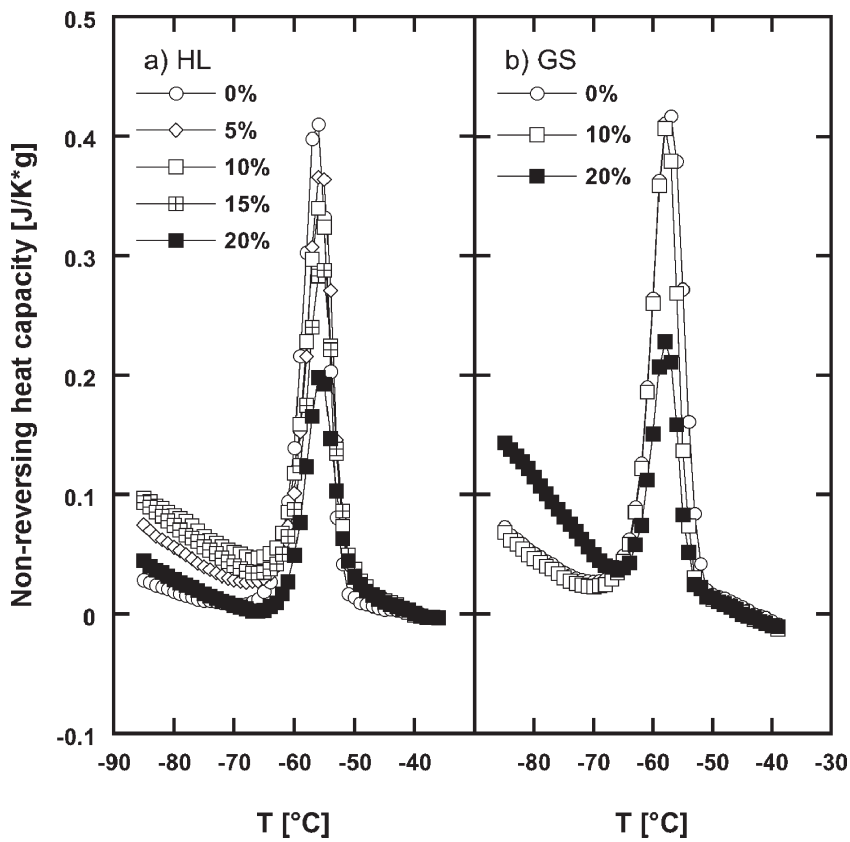

Figure 4. Nonreversing heat capacity of the HBP fraction in HL (a) and GS (b) silica suspensions at different concentrations (vol \% indicated in the graphs).

The peak strength $\Delta H_{\mathrm{r}}$ reported in Table 1 also decreased with increasing amount of HL particles but remained constant upon addition of $10 \mathrm{vol} \%$ of GS. (The decrease observed for $20 \mathrm{vol} \%$ GS and the important enthalpic undershooting in the glassy state 


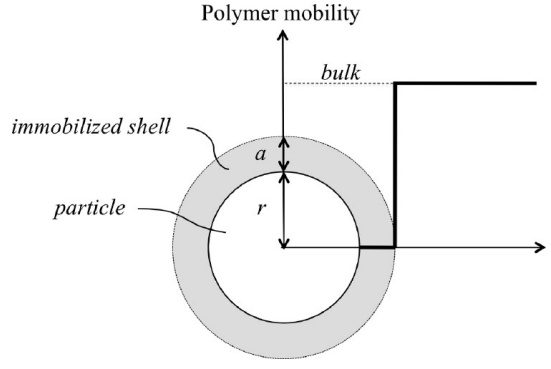

Figure 5. Sketch of the immobilized polymer shell of thickness $a$ on the particle surface and corresponding mobility (thick solid line).

were believed to be artifacts.) The absence of effects for the $10 \mathrm{vol} \%$ GS suspension was also consistent with $\Delta C_{p}$ results (Figure 3c). In the case of $\mathrm{HL}$, the decrease of $\Delta H_{\mathrm{r}}$ was the signature of immobilized HBP molecules and reflected the progressive decrease of the HBP fraction that could undergo aging. The decrease in $\Delta H_{\mathrm{r}}$ occurred even though the suspensions had not been annealed below their $T_{\mathrm{g}}$, in contrast with previous results on silica/poly(vinyl acetate) nanocomposites. ${ }^{62}$ In this latter case the nanoparticles affected the annealing peak only at long time scales, which the authors interpreted as a confirmation of the lack of an immobilized glassy layer at the surface of the particles, which otherwise should have given rise to measurable effects already at small annealing times. Nevertheless, the fact that $\Delta H_{\mathrm{r}}$ decreased with filler content for different annealing times and temperatures confirmed that the particles affected the molecular motion of the polymer matrix.

Immobilized HBP Shell on Silica Nanoparticles. The decrease in $\Delta C_{p}$ at $T_{\mathrm{g}}$ with increasing silica amount reflected a decrease of the polymer mobility due to its interaction with the particles. No attempt was made to determine the details of this reduced mobility, using for instance dynamic light scattering. ${ }^{63}$ Instead, it was assumed that a fraction of the HBP was fully immobilized in the vicinity of the particle surface in the form of a shell of constant thickness as sketched in Figure 5. The existence of an immobilized layer implicitly assumes that there is a sharp interface between the mobile and immobile phases (so-called "two-layer" model). This might be considered as an approximation of the actual gradient in mobility (as indeed revealed by the studies of e. g. Priestley and Torkelson et al., ${ }^{21,26}$ who evidenced a gradient in $T_{\mathrm{g}}$ ). In this case the calculated layer thickness would approximate the characteristic length scale relevant to the change in the system dynamics in the interface region. Another view is that the immobilized layer is really immobilized for the cooperative motions characteristic of the equilibrium state above $T_{\mathrm{g}}$ (see e.g. the study of Sargsyan et $a .^{33}$ ), and this is what is probed by the calorimetric measurements.

The immobilized volume fraction, $\phi_{\mathrm{imm}}$, was calculated assuming that the densities of immobilized and mobile HBP fractions were equal, i.e., from the ratio of $\Delta C_{p}$ at the $T_{\mathrm{g}}$ between the $\mathrm{HBP}$ in the suspensions $\left(\Delta C_{p, \mathrm{HBP}}\right)$ and the pure $\operatorname{HBP}\left(\Delta C_{p, \mathrm{HBP}}^{0}\right)$ :

$$
\phi_{\mathrm{imm}}=1-\Delta C_{p, \mathrm{HBP}} / \Delta C_{p, \mathrm{HBP}}^{0}
$$

This approach is analogous to the calculation of a rigid amorphous fraction in semicrystalline polymers proposed by Sargsyan et al. ${ }^{33}$ Accounting for a density difference between the mobile and immobile fraction does not have a large effect on the final results: density differences of $+20 \%$ and $-20 \%$ change the values of immobilized fraction by approximately $-15 \%$ and $+17 \%$ and of layer thickness by approximately $-12 \%$ and $+13 \%$, respectively. The latter changes are

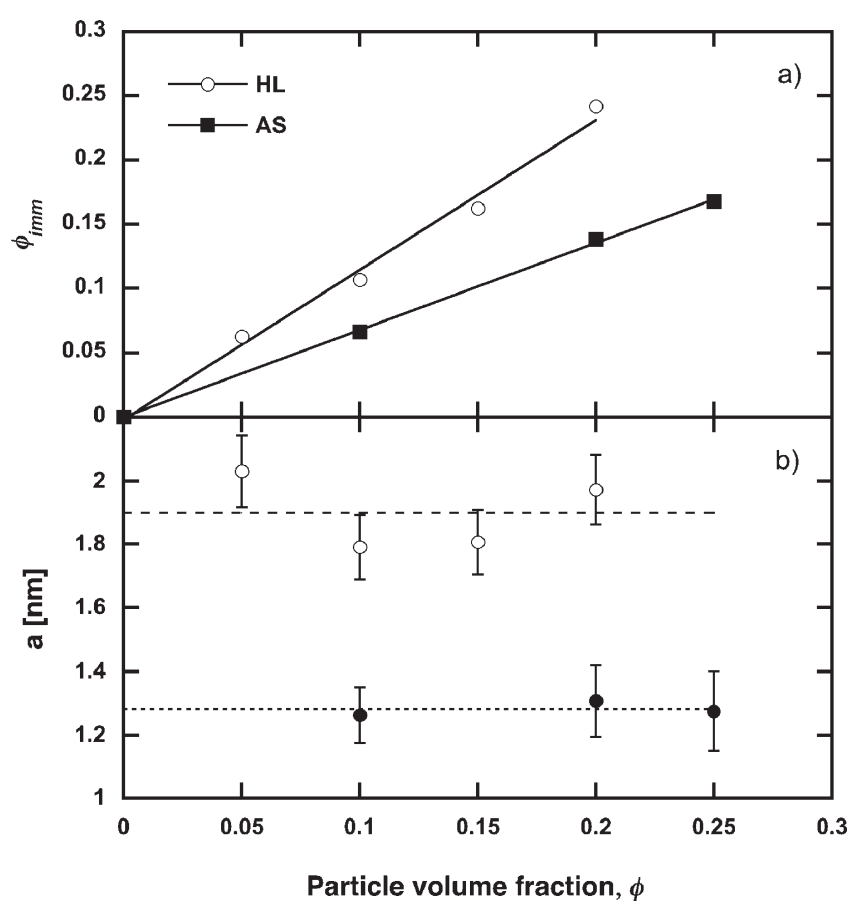

Figure 6. Immobilized volume fraction, $\phi_{\mathrm{imm}}$ (a), and shell thickness, $a$ (b), as a function of HL and AS particle volume fraction, $\phi$. The solid lines are linear fits to the experimental data. The dashed and dotted lines are the average shell thickness for the HL and AS particles, respectively.

comparable to the error on the immobilized layer thickness as will be shown in the following. As shown in Figure 6a for both suspensions the immobilized fraction was found to be proportional to the volume fraction of silica (square of the correlation coefficient $R^{2}$ equal to 0.9904 and 0.9993 for $\mathrm{HL}$ and AS suspensions, respectively) but higher in the case of the HL suspensions. The corresponding thickness of the immobilized shell around individual particles was calculated assuming that all particles have the same radius $r$ :

$$
a=r\left(\left(\frac{\phi_{\mathrm{imm}}}{\phi}+1\right)^{1 / 3}-1\right)
$$

where $\phi$ is the volume fraction of the particles. The HL particles were indeed spherical, and their radius was $6.5 \mathrm{~nm}$ as indicated in the Materials and Methods section. In contrast, the AS particles were in the form of silane-treated aggregates of individual spherical particles of radius equal to $6 \mathrm{~nm}$. An equivalent radius was therefore calculated from the known specific surface $S\left(200 \mathrm{~m}^{2} / \mathrm{g}\right)$ and density $\rho\left(2.2 \mathrm{~g} / \mathrm{cm}^{3}\right)$ of the untreated AS powder as $3 /(\rho S)$ and found to be equal to $6.8 \mathrm{~nm}$. This equivalent radius does not include the thickness of the methacrylsilane layer, the contribution of which was included in the heat capacity of the polymer phase. The data shown in Figure 6b confirm that the thickness of the immobilized shell was independent of the particle volume fraction. It was equal to $1.90 \pm 0.12 \mathrm{~nm}$ for the $\mathrm{HL}$ particles (dashed line in Figure 6b) and to $1.28 \pm 0.11 \mathrm{~nm}$ for the AS particles (dotted line in Figure 6b).

These values of immobilized layer thickness are comparable to the values found in other studies of confined polymers. Indeed, several studies investigated the effect of confinement on the vitrification of glass-forming liquids, both molecular and polymeric. The behavior of liquids confined in nanoporous media and ultrathin films is reviewed in ref 64. A two-layer model, similar to that used in the present work, has been proposed for liquids confined in 
nanopores, in which in the pore center there is a liquid core while a constrained interface layer is present at the pore walls. This model has been used to explain the existence of a glass transition at higher temperature than the $T_{\mathrm{g}}$ of the corresponding bulk materials, assigned to the constrained interface layer. For example, Park and McKenna ${ }^{65}$ studied by differential scanning calorimetry the size and confinements effects on the glass transition of polystyrene/o-terphenyl polymer solutions and found the interacting layer to have a thickness ranging from 2 to $2.5 \mathrm{~nm}$ for the larger pores to $\sim 1 \mathrm{~nm}$ for the smaller pores. Similar findings were reported by $\mathrm{Li}$ and $\mathrm{Simon}^{66}$ for the $T_{\mathrm{g}}$ of bisphenol $\mathrm{M}$ dicyanate ester confined in silanized and in native hydrophilic controlled pore glass $(\mathrm{CPG})$. In this case the constrained layer thickness was found to be $0.9 \pm 0.15 \mathrm{~nm}$. They also observed that for silanized CPG only the smaller pores $(<25 \mathrm{~nm})$ showed the upper $T_{\mathrm{g}}$, highlighting the effect of surface functionalization.

Interestingly, a recent study ${ }^{67}$ pointed out the importance of curvature comparing the immobilized layers formed on 15 $\mathrm{nm}$ silica particles and in a $8 \mathrm{~nm}$ thick film on a flat glass slide. The authors found the layer thickness to be greater on the flat glass $(4-5 \mathrm{~nm})$ than on the small particles $(\sim 1 \mathrm{~nm})$. This trend is similar to that observed by Park and McKenna, ${ }^{65}$ who found a greater layer thickness for larger pores. It seems therefore that the immobilized layer thickness tends to decrease with increasing curvature both for concave (pores) and convex (particles) geometries, although, to the authors' knowledge, a direct comparison for equivalent systems has not been attempted yet.

\section{Discussion}

A vast amount of literature is devoted to the interactions between polymer molecules and inorganic surfaces. In the case of nanocomposites with a very large specific surface, such interactions are expected to influence to a considerable extent the properties of the polymer phase. However, contradictory results are frequently reported in terms of changes in $T_{\mathrm{g}}$ (as reviewed in ref 64) and in the existence of an immobilized polymer fraction in such materials. ${ }^{68}$ For instance, the same epoxy resin was found to form an immobilized interphase with $\mathrm{Al}_{2} \mathrm{O}_{3}$ particles, while no interphase was observed with $\mathrm{SiO}_{2}$ particles. ${ }^{69,70}$ Bogoslovov et al. showed that in poly(vinyl acetate) $/ \mathrm{SiO}_{2}$ nanocomposites there was no evidence that the local segment dynamics of chains adjacent to the filler differ from the bulk matrix, using heat capacity, thermal expansion coefficient, and relaxation time measurements. ${ }^{71}$ In contrast, for $\mathrm{PMMA} / \mathrm{SiO}_{2}$ nanocomposites, a broadening of the glass transition was observed and attributed to hydrogen bonding between the matrix and the filler. ${ }^{72,73}$ In this case, it was concluded that the different sensitivity of experimental techniques (FTIR vs MDSC) may have resulted in different conclusions about surface effects. ${ }^{72}$

These contradictory results can in fact be reconciled when the nature of the polymer-inorganic surface interactions is clarified. It was shown that the substitution of the surface hydroxyls of silica with trimethylsilyl groups determined immobilization effects in PMA-based nanocomposites that were intermediate between the bulk polymer and nanocomposites with untreated silica. ${ }^{73}$ As reported by $\mathrm{Oh}$ and Green, the degree of grafting and the size of the molecules used for nanoparticle surface functionalization strongly influence the thermal behavior, relaxation dynamics, and viscosity in unentangled polymers. ${ }^{74}$ Small molecules used for surface treatment may behave as "dry brushes" with respect to the host polymer, the $T_{\mathrm{g}}$ of which decreases and viscosity weakly depends on the filler amount. On the contrary, large molecules can wet the embedding polymer, leading to increased $T_{\mathrm{g}}$, relaxation times, and viscosity. These effects can

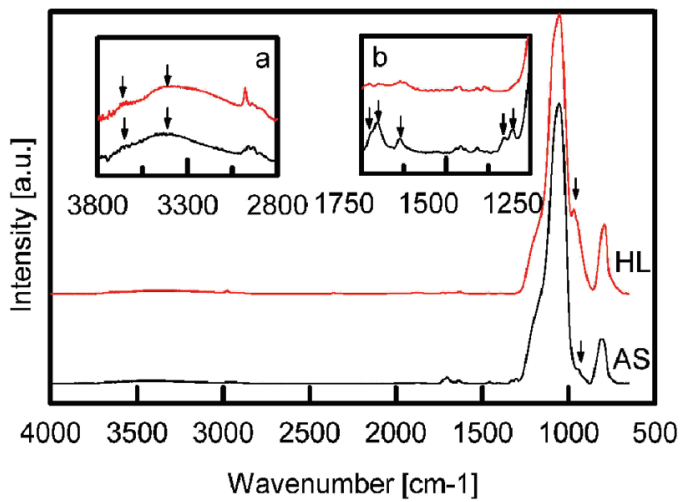

Figure 7. FTIR-ATR spectra of the HL and AS silica powders.

be very large already at filler contents as low as $3 \mathrm{wt} \%$. It was moreover observed that if the polymer has comparable or lower degree of polymerization (DP) with respect to the grafted molecules, the $T_{\mathrm{g}}$ of the nanocomposite was increased, and when DP was higher, the opposite effect was observed. ${ }^{75}$

The different degree of immobilization for the HL and AS suspensions confirms the main influence of the particle surface chemistry and resulting interfacial interactions. The FTIR-ATR spectra of AS and HL silica are shown in Figure 7. Both silica powders exhibited the characteristic $\mathrm{Si}-\mathrm{O}-\mathrm{Si}$ asymmetric stretching bands in the $1290-1000 \mathrm{~cm}^{-1}$ region and symmetric $\mathrm{Si}-\mathrm{O}-\mathrm{Si}$ stretching vibration at $794 \mathrm{~cm}^{-1} .76$ The broad bands at 3600 and $3400 \mathrm{~cm}^{-1}$ (inset a of Figure 7) due to the hydroxyl stretching vibrations of hydrogen-bonded $\mathrm{Si}-\mathrm{OH}$ groups and of adsorbed water were largely overlapping. Therefore, they could not be used for the quantification of the surface silanols. ${ }^{77}$ On the one hand, the spectrum of HL however showed a peak at $970 \mathrm{~cm}^{-1}$ that was attributed to $\mathrm{Si}-\mathrm{O}$ stretching ${ }^{76-78}$ in the $\mathrm{Si}-\mathrm{OH}$ groups. This peak was extremely weak in the spectrum of AS. It was thus inferred that HL silica had a greater amount of surface silanols than AS silica. On the other hand, the AS spectrum showed the characteristic peaks of the methacrylate group (inset b of Figure 7) due to the surface modification with a methacrylate functional silane. The $\mathrm{C}=\mathrm{O}$ stretching appeared at $1722 \mathrm{~cm}^{-1}$ for free $\mathrm{C}=\mathrm{O}$ groups and at $1703 \mathrm{~cm}^{-1}$ for hydrogenbonded $\mathrm{C}=\mathrm{O}$ groups. ${ }^{79}$ The peak at about $1640 \mathrm{~cm}^{-1}$ was the result of the overlapping of the $\mathrm{C}=\mathrm{C}$ stretching band and of the $\mathrm{H}-\mathrm{O}-\mathrm{H}$ bending mode of adsorbed water, and the peaks at 1326 and $1302 \mathrm{~cm}^{-1}$ were attributed to $\mathrm{C}-\mathrm{O}$ stretching frequencies. From the presence of both free and hydrogen-bonded $\mathrm{C}=\mathrm{O}$ groups it was inferred that some of the silane chains were standing perpendicular to the silica surface only bound by the silane head ("extended configuration"), while others laid parallel to the surface with the methacrylate end attached to the surface through hydrogen bonding. ${ }^{80,81}$

A tentative sketch of the interfacial structure for the investigated systems is depicted in Figure 8. In the case of HL particles with silanol groups on the surface, the prevalent interaction with the acrylated chain ends of the HBP was H-bonding, ${ }^{82}$ which was stronger than the intermolecular interactions between adjacent HBP molecules. This kind of interaction was already observed for nanocomposites containing untreated silica particles and polymer matrices with carbonyl groups by FTIR, NMR, and DSC. ${ }^{72,73}$ In the present case, part of the HBP branches were $\mathrm{H}$-bonded to the nanoparticles, and these branches were all connected to the core of the HBP. The other branches were not immobilized. Because of this asymmetry, and disregarding the polydispersity of the HBP, the immobilized shell should correspond to the length of one branch, i.e., half of the length of a monolayer of HBP molecules. The average thickness of the shell was found to be 

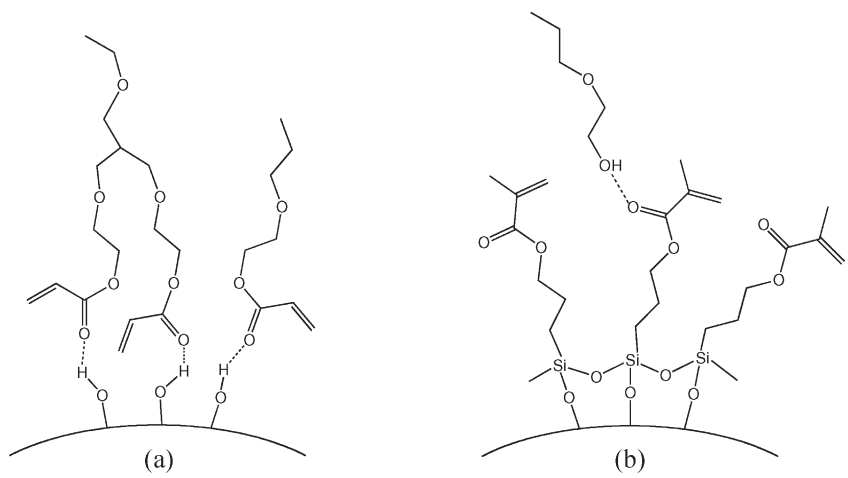

Figure 8. Tentative interactions in immobilized shells around a silica particle: H-bonding between the acrylated HBP (the ends of three branches of the molecule are depicted) and the silanol surface of a HL particle (a); covalent bonding of the methacrylsilane to the AS particle and H-bonding with one HBP branch (b).

equal to $1.9 \mathrm{~nm}$, which is indeed comparable to half the size of the HBP molecule, around $4 \mathrm{~nm}$ (see e.g., ref 83).

In the case of the methacrylsilane-treated AS particles, the silane molecule was covalently attached to the silica surface due to hydrolysis and condensation reactions. ${ }^{84}$ The $\mathrm{Si}-\mathrm{O}$ covalent bond was, again, stronger than the intermolecular interactions between the methacrylate group of the silane and the acrylated chain ends of the HBP. Additional H-bonds may also be present between the methacrylate groups and residual $\mathrm{OH}$ groups of the HBP. The average thickness of the shell was found to be equal to $1.3 \mathrm{~nm}$, which is comparable with the length of the methacrylsilane close to $1 \mathrm{~nm}$. It may correspond to the extended configuration of the silane favored by the small difference in solubility parameters between the acrylate and methacrylate functions. ${ }^{85}$

The present results are also to be commented in light of the rheological behavior of the HL and AS suspensions under shear. ${ }^{44}$ A liquid-to-solid transition was found to occur below $10 \mathrm{vol} \%$ of particles for the HL suspension and in the $20-25 \mathrm{vol} \%$ range for the AS suspensions, i.e., far below the $64 \%$ threshold for concentrated "hard-sphere" suspensions. These results were also analyzed in terms of an immobilized layer at the surface of the particles, leading to layer thicknesses of $7.5 \mathrm{~nm}$ (HL) and $3.3 \mathrm{~nm}$ (AS). These two values are quite different from the values calculated in the present study, which could be expected since the molecular scales relevant for shear viscosity and heat capacity are also different. In any case the present finding of a higher immobilized fraction in the HL suspensions remains consistent with these rheological data. A further point to be mentioned is on the influence of particle agglomeration, which was particularly pronounced in the case of the AS suspensions (see Figure 1). In this case, the shell thickness was found to be independent of particle fraction using either rheology ${ }^{44}$ or the present calorimetry analysis. This result shows that particle agglomeration did not play a significant role in the local dynamics of the investigated suspensions (hence on the heat capacity) and that it was primarily the interfacial interactions and resulting immobilized shell which dominated the observed behavior.

\section{Conclusions}

The existence of immobilized HBP molecules in HL and AS silica nanosuspensions and GS microsuspensions was investigated using precise measurements of the heat capacity step $\Delta C_{p}$ of the polymer phase at the glass transition. A systematic decrease of $\Delta C_{p}$ was observed with increasing particle fraction for both HL and AS nanoparticles, which was assumed to be proportional to a fraction of immobilized molecules in a shell around the particles. The reduced strength of the enthalpy relaxation of the HL nanosuspensions confirmed the partial suppression of chain dynamics in these materials. In contrast, the effect of immobilization could not be observed on GS microsuspensions due to the small specific surface of the GS particles. The thickness of the immobilized layer was $1.9 \mathrm{~nm}$ for HL particles and $1.3 \mathrm{~nm}$ for AS particles and reflected the different interfacial interactions. The untreated silica (HL) was hydrogen bonded with the acrylated HBP, immobilizing part of the first HBP molecular layer around the particles. In the case of silylated particles (AS), the immobilized layer corresponded roughly to the length of the methacrylsilane molecule. The evidence for immobilization effects was in qualitative agreement with rheological results obtained previously on the same suspensions and underlined the important role played by interfacial interactions in nanocomposite materials.

Acknowledgment. Financial support from the Swiss National Science Foundation (SNF project \# 200020-119780) is gratefully acknowledged. Furthermore, the authors thank Henrik Bernquist from Perstorp AB for useful advice and the supply of samples.

\section{References and Notes}

(1) Burmistr, M. V.; Sukhyy, K. M.; Shilov, V. V.; Pissis, P.; Spanoudaki, A.; Sukha, I. V.; Tomilo, V. I.; Gomza, Y. P. Polymer 2005, 46, 12226.

(2) Houphouet-Boigny, C.; Plummer, C. J. G.; Wakeman, M. D.; Månson, J.-A. E. Polym. Eng. Sci. 2007, 47, 1122.

(3) Brechet, Y.; Cavaillé, J.-Y.; Chabert, E.; Chazeau, L.; Dendievel, R.; Flandin, L.; Gauthier, C. Adv. Eng. Mater. 2001, 3, 571.

(4) Plummer, C. J. G.; Rodlert, M.; Bucaille, J.-L.; Grünbauer, H. J. M.; Månson, J.-A. E. Polymer 2005, 46, 6543.

(5) Chen, G.; Wu, C.; Weng, W.; Wu, D.; Yan, W. Polymer 2003, 44, 1781.

(6) Hong, C. H.; Lee, Y. B.; Bae, J. W.; Jho, J. Y.; Nam, B. U.; Hwang, T. W. J. Appl. Polym. Sci. 2005, 98, 427.

(7) Messersmith, P. B.; Giannelis, E. P. J. Polym. Sci., Part A: Polym. Chem. 1995, 33, 1047.

(8) Alexandre, M.; Dubois, P. Mater. Sci. Eng. 2000, 28, 1.

(9) Jordan, J.; Jacob, K.-I.; Tannenbaum, R.; Sharaf, M. A.; Jasiuk, I. Mater. Sci. Eng., Part A 2005, 393, 1.

(10) Hussain, F.; Hojjati, M.; Okamoto, M.; Gorga, R. E. J. Compos. Mater. 2006, 40, 1511.

(11) Cho, J.; Joshi, M. S.; Sun, C. T. Compos. Sci. Technol. 2006, 66, 1941.

(12) Lazzeri, A.; Thio, Y. S.; Cohen, R. E. J. Appl. Polym. Sci. 2004, 91, 925.

(13) Pluta, M.; Galeski, A.; Alexandre, M.; Paul, P. A.; Dubois, P. J. Appl. Polym. Sci. 2002, 86, 1497.

(14) Anderson, B. J.; Zokoski, C. F. Macromolecules 2008, 41, 9326.

(15) Cai, J. J.; Salovey, R. J. Polym. Sci., Part B: Polym. Phys. 1999, 37 , 815

(16) Rodlert, M.; Plummer, C. J. G.; Leterrier, Y.; Månson, J.-A. E.; Grünbauer, H. J. M. J. Rheol. 2004, 48, 1049.

(17) Osman, M. A.; Atallah, A. Polymer 2006, 47, 2357.

(18) Li, C. Y.; Chou, T. W. Appl. Phys. Lett. 2007, 90, 174108.

(19) Bansal, A.; Yang, H.; Li, C.; Benicewiz, B. C.; Kumar, S. K.; Schadler, L. S. Nature Mater. 2005, 4, 693.

(20) Kropka, J. M.; Pryamitsyn, V.; Ganesan, V. Phys. Rev. Lett. 2008, 101,075702

(21) Rittigstein, P.; Pristley, R. D.; Broadbelt, L. J.; Torkelson, J. M. Nature Mater. 2007, 6, 278.

(22) Van Zanten, J. H.; Wallace, W. E.; Wu, W. Phys. Rev. E 1996, 53, R2053.

(23) Kim, J. H.; Jang, J.; Zin, W.-C. Langmuir 2001, 17, 2703.

(24) Berriot, J.; Montes, H.; Lequeux, F.; Long, D.; Sotta, P. Macromolecules 2002, 35, 9756.

(25) Berriot, J.; Montes, H.; Lequeux, F.; Long, D.; Sotta, P. Europhys. Lett. 2003, 64, 50.

(26) Priestley, R. D.; Ellison, C. J.; Broadbelt, L. J.; Torkelson, J. M. Science 2005, 309, 456.

(27) Koh, Y. P.; Simon, S. L. J. Polym. Sci., Part B: Polym. Phys. 2008, 46, 2741.

(28) Huang, Y.; Paul, D. R. Polymer 2004, 45, 8377. 
(29) Huang, Y.; Paul, D. R. Macromolecules 2005, 38, 10148.

(30) Berriot, J.; Lequeux, F.; Monnerie, L.; Montes, H.; Long, D.; Sotta, P. J. Non-Cryst. Solids 2002, 307, 719.

(31) Sotta, P.; Fülber, C.; Demco, D. E.; Blümuch, B.; Spiess, H. W. Macromolecules 1996, 29, 6222.

(32) Ltivinov, V. M.; Steeman, P. A. M. Macromolecules 1999, 32, 8476.

(33) Sargsyan, A.; Tonoyan, A.; Davtyan, S.; Schick, C. Eur. Polym. J. 2007, 43, 311 .

(34) Plummer, C. J. G.; Ruggerone, R.; Negrete-Herrera, N.; Bourgeat-Lami, E.; Månson, J.-A. E. Macromol. Symp. 2010, 294, 1-10.

(35) Fragiadakis, D.; Pissis, P. J. Non-Cryst. Solids 2007, 353, 4344

(36) Li, Y.; Ishida, H. Macromolecules 2005, 38, 6513.

(37) Plummer, C. J. G.; Luciani, A.; Nguyen, T.; Garamszegi, L.; Rodlert, M.; Månson, J.-A. E. Polym. Bull. 2002, 49, 77.

(38) Bosman, A. W.; Jansen, H. M.; Meijer, E. W. Chem. Rev. 1999, 99, 1665

(39) Voit, I. B. Acta Polym. 1995, 46, 87.

(40) Mezzenga, R.; Boogh, L.; Månson, J.-A. E. Compos. Sci. Technol. 2001, 61, 787.

(41) Geiser, V.; Leterrier, Y.; Månson, J.-A. E. J. Appl. Polym. Sci. 2009, 114, 1954

(42) Schmidt, L. E.; Schmah, D.; Leterrier, Y.; Månson, J.-A. E. Rheol. Acta 2007, 46, 693

(43) Schmidt, L. E.; Yi, S.; Jin, Y. H.; Leterrier, Y.; Månson, J.-A. E. Micromech. Microeng. 2008, 18, 45022

(44) Geiser, V.; Leterrier, Y.; Månson, J.-A. E. Macromolecules 2010, 43, 7705 .

(45) Bicerano, J.; Douglas, J. F.; Brune, D. A. J. Macromol. Sci., Rev. Macromol. Chem. Phys. 1999, C39, 561.

(46) Bansal, N. P.; Doremus, R. H. Handbook of Glass Properties; Academic Press: New York, 1986; Vol. 16.

(47) Andrieux, D.; Jestin, J.; Kervarec, N.; Pichon, R.; Privat, M.; Olier, R. Langmuir 2004, 20, 10591.

(48) Donatti, D. A.; Ibañez Ruiz, A.; Vollet, D. R. J. Non-Cryst. Solids 2005, 351, 1226 .

(49) Dékany, I.; Turi, L. Colloids Surf., A 1997, 126, 59.

(50) Wang, L.; Tan, Z. C.; Meng, S. H.; Druzhinina, A.; Varshchenko, L. A.; Li, G. H. J. Non-Cryst. Solids 2001, 296, 139.

(51) Wunderlich, B.; Jin, Y.; Boller, A. Thermochim. Acta 1994, 238, 277.

(52) Reading, M.; Luget, A.; Wilson, R. Thermochim. Acta 1994, 238, 295.

(53) Schawe, J. E. K. Thermochim. Acta 1995, 261, 18.

(54) Hutchinson, J. M. J. Therm. Anal. Calorim. 2009, 98, 579.

(55) Hutchinson, J. M.; Montserrat, S. Thermochim. Acta 1996, 286, 263

(56) Hutchinson, J. M.; Montserrat, S. Thermochim. Acta 2001, 377, 63.

(57) Pradhan, N. R.; Iannacchione, G. S. J. Phys. D 2010, 43, 105401.
(58) Simon, S. L.; McKenna, G. B. Thermochim. Acta 2000, 348, 77.

(59) Simon, S. L.; McKenna, G. B. Thermochim. Acta 1997, 307, 1.

(60) Day, M.; Nawaby, A. V.; Liao, X. J. Therm. Anal. Calorim. 2006, 86,623 .

(61) Chen, Y.; Zhou, S.; Yang, H.; Gu, G.; Wu, L. J. Colloid Interface Sci. 2004, 279, 370 .

(62) Amanuel, S.; Gaudette, A. N.; Sternstein, S. S. J. Polym. Sci., Part B: Polym. Phys. 2008, 46, 2733.

(63) Savin, D. A.; Pyun, J.; Patterson, G. D.; Kowalewski, T.; Matyjaszewski, K.J. Polym. Sci., Part B: Polym. Phys. 2002, 40, 2667.

(64) Alcoutlabi, M.; McKenna, G. B. J. Phys.: Condens. Matter 2005, 17, R461.

(65) Park, J. Y.; McKenna, G. B. Phys. Rev. B 2000, 61, 6667

(66) Li, Q. X.; Simon, S. L. Macromolecules 2009, 42, 3573.

(67) Harton, S. E.; Kumar, S. K.; Yang, H. C.; Koga, T.; Hicks, K.; Lee, E.; Mijovic, J.; Liu, M.; Vallery, R. S.; Gidley, D. W. Macromolecules 2010, 43, 3415.

(68) Leszczynska, A.; Pielichowski, K. J. Therm. Anal. Calorim. 2008, 93, 677 .

(69) Baller, J.; Becker, N.; Zhiemer, M.; Thomassey, M.; Zielinski, B.; Müller, U.; Sanctuary, R. Polymer 2009, 50, 3211.

(70) Sanctuary, R.; Baller, J.; Krüger, J. K.; Schaefer, D.; Bactavatchalou, R.; Wetzel, B.; Possart, W.; Alnot, P. Thermochim. Acta 2006, 445, 111.

(71) Bogoslovov, R. B.; Roland, C. M.; Ellis, A. R.; Randall, A. M.; Robertson, C. G. Macromolecules 2008, 41, 1289.

(72) Blum, F. D.; Krisanangkura, P. Thermochim. Acta 2009, 492, 55.

(73) Metin, B.; Blum, F. D. Langmuir 2010, 26, 5226.

(74) Oh, H.; Green, P. F. Nature Mater. 2009, 8, 139

(75) Bansal, A.; Yang, H.; Li, C.; Benicewicz, B. C.; Kumar, S. K.; Schadler, L. S. J. Polym. Sci., Part B: Polym. Phys. 2006, 44, 2944.

(76) Bertoluzza, A.; Fagnano, C.; Morelli, M. A.; Gottardi, V.; Guglielmi, M. J. Non-Cryst. Solids 1982, 48, 117.

(77) Perry, C. C.; Li, X. C. J. Chem. Soc., Faraday Trans. 1991, 87, 761.

(78) Decottignies, M.; Phalippou, J.; Zarzycki, J. J. Mater. Sci. 1978, 13, 2605.

(79) Colthup, N. B.; Daly, L. H.; Wiberley, S. E. Introduction to Infrared and Raman Spectroscopy; Academic Press: Boston, 1990.

(80) Söderholm, K. J. M.; Shang, S. W. J. Dent. Res. 1993, 72, 1050.

(81) Liu, Q.; Ding, J.; Chambers, D. E.; Debnath, S.; Wunder, S. L.; Baran, G. R. J. Biomed. Mater. Res. 2001, 57, 384.

(82) Sideridou, I. D.; Karabela, M. M. J. Appl. Polym. Sci. 2008, 110, 507.

(83) Gusev, S. I.; Zaitsev, S. D.; Semchikov, Y. D.; Zakharova, O. G. Russ. J. Appl. Chem. 2006, 79, 1338.

(84) Ishida, H.; Miller, J. D. Macromolecules 1984, 17, 1659.

(85) Lewin, J. L.; Maerzke, K. A.; Schultz, N. E.; Ross, R. B.; Siepmann, J. I. J. Appl. Polym. Sci. 2010, 116, 1. 